\title{
BENEFÍCIOS DA IMPLANTAÇÃO DO PLANEJAMENTO E CONTROLE DA PRODUÇÃO (PCP): UM ESTUDO DE CASO EM UMA EMPRESA DE CONFECÇÃO
}

MACHADO, Ana Carolina Benevenuto ${ }^{1}$

CABRAL, Renata Rodrigues ${ }^{2}$

MOREIRA, Andreia Aparecida Silva ${ }^{3}$

MACHADO, Ana Carolina Benevenuto. CABRAL, Renata Rodrigues. MOREIRA, Andreia Aparecida Silva. Benefícios da implantação do planejamento e controle da produção (PCP): um estudo de caso em uma empresa de confecção. Revista Científica Multidisciplinar Núcleo do Conhecimento. Ano 03, Ed. 09, Vol. 07, pp. 53-69 Setembro de 2018. ISSN:2448-0959

\section{RESUMO}

Este artigo tem como objetivo descrever a implantação do PCP em uma empresa de confecção e apresentar quais os benefícios essa ferramenta pode trazer, porém existem dificuldades que podem atrapalhar o processo de implantação. Para isso, foi realizada uma pesquisa descritiva com abordagem qualitativa de caráter exploratório através de um estudo de caso. A empresa em estudo não possui um planejamento e controle da produção bem estruturado, e foi possível perceber que a maior dificuldade na implantação do PCP encontra-se na resistência, por parte da diretoria, em mudar os processos. Portanto, foi possível concluir que a implantação do PCP na indústria de confecção irá controlar e programar a produção da empresa, também ajudará na

\footnotetext{
${ }^{1}$ Graduanda em Administração na Universidade do Estado de Minas Gerais (Uemg).

${ }^{2}$ Graduanda em Administração na Universidade do Estado de Minas Gerais (Uemg).

${ }^{3}$ Professora na Universidade do Estado de Minas Gerais (Uemg).
} 
rotina de trabalho, garantindo maior qualidade no produto final, sem atrasos, e consequentemente, manterá a empresa competitiva no mercado.

Palavras chave: Planejamento e Controle da Produção, Implantação, Dificuldades, Benefícios.

\section{INTRODUÇÃO}

O planejamento e controle da produção (PCP) envolve etapas diversas, dentre as quais: planejamento, programação e controle do que foi estabelecido, não deixando o objetivo final ser desviado do plano, a fim de que não ocorram dificuldades de se manter no mercado e adquiram bons resultados.

Sendo assim, "o PCP tem como função a organização, padronização e sistematização do processo, levando a empresa a produzir com mais qualidade, segurança, rapidez, facilidade, correção e menor custo." (PORTOPÉDIA, 2016, p. 6).

A Empresa em estudo é uma Confecção sediada no município de Divinópolis Minas Gerais. Atua no mercado nacional produzindo e comercializando modinha feminina. É uma empresa familiar. Possui 3 sócios e 50 funcionários. Está no mercado há trinta anos, procurando sempre aprimorar e melhorar sua produção, e para que isso aconteça é necessário realizar um bom planejamento antes de iniciar quaisquer atividades, obtendo assim, excelentes resultados e atingindo as expectativas esperadas. Por isso, justifica-se a proposta de implantação do PCP.

Considerando o PCP como uma importante ferramenta para as empresas, acreditase que essa realidade pode ser melhor entendida a partir do seguinte problema: "Quais os benefícios da implantação do PCP em uma empresa de confecção"?

O objetivo geral do estudo consiste em descrever como se dá a implantação do Planejamento e Controle de Produção e quais benefícios pode proporcionar em uma empresa do ramo de confecção. 
Constituem objetivos específicos deste estudo: a) Caracterizar os fundamentos teóricos sobre PCP e associá-los à realidade da empresa em estudo; b) Descrever as finalidades e as funções do PCP; c) Analisar as dificuldades encontradas na implantação do PCP.

Desta forma, têm-se as seguintes hipóteses: a) A empresa em estudo não tem um planejamento e controle da produção bem estruturado; b) As dificuldades na implantação do PCP na empresa de confecção encontram-se na resistência, por parte da diretoria, em mudar os processos; c) A empresa desconhece as funções e os benefícios do PCP, por acreditarem que seus processos estejam bem estruturados.

O estudo sobre a implantação do PCP na Empresa de Confecção é de extrema importância, pois conhecer os benefícios dessa ferramenta, permite obter resultados positivos, organização da produção e planejamento adequado. Permite, também, um aprofundamento de conhecimentos sobre o PCP, valioso conteúdo da disciplina de Administração da Produção, além de ser uma importante ferramenta para relacionar teoria e prática.

O procedimento metodológico para coleta e operacionalização das informações dessa pesquisa será baseado em estudo de caso, com aplicação de entrevista ao Analista de PCP, Gerente de Produção e os 3 Diretores da empresa. Além da pesquisa qualitativa de caráter exploratório e revisão de literatura.

O artigo está estruturado da seguinte forma: Introdução contendo o problema, as hipóteses, os objetivos e a justificativa. A segunda parte tem-se o referencial teórico que discorre sobre o tema baseando-se em autores renomados como: Moreira 2016, Slack, Brandon-Jones e Johnston 2016, dentre outros. A terceira parte a metodologia baseada em estudo de caso. $\mathrm{Na}$ quarta parte os resultados e discussões com aplicação de entrevistas. Finalizando é exposta a conclusão, seguida pelas referências. 


\section{REFERENCIAL TEÓRICO}

Nesta parte são apresentadas as principais reflexões sobre o tema desta pesquisa, como administração da produção, conceitos, funções e princípios de PCP, qualidade e benefícios da ferramenta bem como dificuldades na implantação.

\subsection{PCP}

Em qualquer atividade, principalmente a econômica, o planejamento exerce grande importância. O planejamento e controle da produção (PCP) é essencial para todas as organizações para que possam exercer, com segurança e qualidade, suas atividades a fim de atenderem seus clientes e se fortalecerem no mercado onde estão inseridas. Através do PCP, é possível tomar decisões adequadas, propiciando o desenvolvimento das empresas. (CHIAVENATO, 2005).

\subsubsection{ADMINISTRAÇÃO DA PRODUÇÃO}

As origens do PCP são difíceis de serem identificadas, pois sempre houveram organizações gerando e entregando produtos. Frederick Taylor e Ford muito contribuíram para que a produção em massa se estabelecesse de forma global, colaborando para a progressão da gestão das indústrias. (CORRÊA e CORRÊA, 2012).

Para Moreira (2016), a administração da produção está voltada para a produção de um bem físico, relaciona-se com atividades industriais e se concentram na fábrica ou na planta industrial.

Slack, Brandon-Jones e Johnston (2016) afirmam que a administração da produção é muito importante tanto em pequenas quanto em grandes organizações. É ela que gerencia recursos que criam e entregam serviços e produtos, os quais possuem uma grande diferença, pois produtos são tangíveis e serviços são intangíveis. 
A administração da produção e operações referem-se às funções administrativas clássicas (planejar, organizar, dirigir e controlar) aplicadas às atividades envolvidas com a produção de um produto ou à prestação de serviço. Como os conceitos e técnicas aplicam-se à tomada de decisão facilita a aquisição de melhores resultados. (MOREIRA, 2016).

\subsubsection{O PLANEJAMENTO E CONTROLE DA PRODUÇÃO}

Slack, Brandon-Jones e Johnston (2016) definem o planejamento como uma preparação do que deve acontecer em um tempo futuro, baseado em expectativas, que pode ou não acontecer como esperado. Pode ocorrer vários empecilhos ao longo dos processos como máquinas quebradas, funcionários doentes, atraso de fornecedores e, assim, os planos precisam ser refeitos. O controle ajusta as operações para que os objetivos sejam atingidos como planejado, a saber, conserto de máquinas, contratação de funcionários terceirizados, procura de um novo fornecedor de entrega mais rápida.

O propósito do planejamento pode ser definido como o desenvolvimento de processos, técnicas e atitudes administrativas, as quais proporcionam uma situação viável de avaliar as implicações futuras de decisões presentes em função dos objetivos empresariais que facilitam a tomada de decisão no futuro, de modo mais rápido, coerente, eficiente e eficaz. (OLIVEIRA, 2015, p. 5).

Planejamento da capacidade é um estudo da capacidade máxima que se pode ser produzida em um determinado período. Para esse estudo, são realizados cálculos para saber quantos funcionários farão um determinado produto, quantas horas serão trabalhadas para produzi-lo. Se houver necessidade de aumentar a produção, a alternativa é aumentar o número de funcionários ou de horas extras. (MOREIRA, 2016).

O planejamento agregado considera a produção e a demanda, fazendo com que os dois fatores estejam relacionados e interligados. Dessa forma, é feita uma estimativa 
da demanda que pode sofrer alterações por diversos motivos como momento econômico, variação errática e sazonalidades. Empresas com linha de produtos variados não viabilizam a utilização deste sistema de planejamento, pois há dificuldades em comparar a produção e a demanda de cada produto, fugindo da atribuição de agregado. O planejamento agregado está entre planejamento de capacidade e o planejamento máster e preenche uma lacuna para buscar o máximo da produção sem que o prazo médio seja alterado. (MOREIRA, 2016).

Ao estabelecer estes dados, será criado o Plano-Mestre da Produção (PMP), que forma o principal input ao Materials requirements plannig (MRP) ou Planejamento das necessidades de material. O MRP calcula quanto de material será necessário e em qual momento precisará ser solicitado para a produção prevista de pedidos, ajudando nos cálculos de volume e na organização do tempo da demanda futura. (SLACK, BRANDON-JONES e JOHNSTON, 2016).

De acordo com Moreira (2016), o PMP é um documento que descreve quais e quantos itens serão produzidos em um período, de modo bem simples. Até a elaboração de um PMP que supra as necessidades é necessária uma pesquisa bem elaborada de toda a produção, principalmente de sua capacidade produtiva. A partir do momento que estiver tudo pronto, é indispensável programar e controlar a produção para que tudo ocorra como o esperado.

\subsubsection{FUNÇÕES E PRINCÍPIOS DO PCP}

São funções do PCP: definição das quantidades a produzir; gestão de estoque; emissão de ordens de produção; programação das ordens de fabricação; movimentação das ordens de fabricação; acompanhamento da produção. (RUSSOMANO, 1995 apud BOLSI, 2011).

Para desempenhar sua função de coordenação de forma eficaz, o PCP deve ser o centro de convergência de informações provenientes das diversas áreas do sistema produtivo, tais como Produção, Marketing, Finanças, Compras, Manutenção, Recursos Humanos, Engenharia do 
Produto e Processo, Vendas, entre outras. Tais informações expressas através do planejamento da produção passam também a ser objetivo maior seguido por estas áreas. (TUBINO, 2000 apud BOLSI, 2011, p. 30).

Segundo Oliveira (2015), para atingir os resultados esperados, deve-se respeitar alguns princípios, apresentados a seguir:

1. Princípio da contribuição aos objetivos: visar, ao máximo, os objetivos da empresa;

2. Princípio da precedência do planejamento: em primeiro lugar, planejar; depois, organizar, dirigir e controlar;

3. Princípio das maiores influências e abrangência: o planejamento pode provocar modificações nas características e atividades da empresa (pessoas, tecnologias e sistemas);

4. Princípio da maior eficiência, eficácia e efetividade: maximizar os resultados e minimizar as deficiências, proporcionando a melhoria da empresa.

Ackof apud Oliveira (2015) apresenta ainda quatro princípios como específicos, que proporciona base mais sólida para o processo decisório ligado aos processos de planejamento da empresa:

1. Planejamento participativo: o principal objetivo é o processo de desenvolvimento, ou seja, é preciso que que haja "condições que facilitem o processo de elaboração pela própria organização." (OLIVEIRA, 2015, p. 2).

2. Planejamento coordenado: todos os aspectos devem atuar interdependentes;

3. Planejamento integrado: estabelecer os objetivos e os meios para alcançá-los, de forma coesa;

4. Planejamento permanente: o próprio ambiente empresarial exige que a empresa esteja sempre planejando. 


\subsubsection{PCP ATRELADO À QUALIDADE}

O Planejamento e Controle da Produção tem grande importância dentro de uma empresa, pois coordena recursos que interferem nos resultados da organização e auxiliam para que haja qualidade nos seus resultados. (PEREIRA, BARBOSA e DROHOMERETSKI, 2012).

Para Rocha e Galende (2014), qualidade, segurança, eficácia e credibilidade de um produto são muito importantes. Desse modo, é preciso a realização do controle de qualidade para que as indústrias assegurem, junto aos seus consumidores, a aceitação do seu produto.

Redução de tempo e desperdícios, qualidade do ambiente, padronização dos procedimentos e otimização de processos são as principais vantagens do controle de qualidade que, atreladas ao Planejamento e Controle da Produção asseguram que os produtos estejam dentro dos padrões de qualidade exigidos e, consequentemente, a satisfação dos clientes. (ROCHA e GALENDE, 2014).

\subsubsection{BENEFÍCIOS DO PCP}

Através de um sistema de produção eficiente, o PCP planeja e programa a produção para que os níveis de estoque não aumente de forma desnecessária. Através do controle, os materiais necessários chegam corretamente e em quantidade exata até a linha de montagem, para que sejam eliminadas as chances de desperdícios (BOCK, FERRARI, NARA e KIPPER, 2015).

Segundo Chiavenato (2005), vários são os benefícios que o PCP pode proporcionar a uma organização, a saber:

1. Diminuição do tempo de produção: com o planejamento, o tempo gasto com atividades não planejadas são minimizados; assim, o tempo ganho é gasto na produção e também na tomada de decisões; 
2. Diminuição de fila de espera em máquinas utilizadas: como é realizado o planejamento para o uso de cada máquina, o desempenho é determinado eliminando o tempo de espera e efetivando a capacidade de produção;

3. Cumprimento dos prazos de entrega: com o prazo de entrega cumprido, boa parte da satisfação do cliente é garantida, aumentando a cartela de clientes e, consequentemente, a produção;

4. Diminuição do tempo de setup das máquinas: o tempo gasto com ajustes em máquinas é reduzido, sendo assim pode ser utilizado em outras necessidades;

5. Diminuição das despesas: com a produção programada, reduzem-se os custos ligados à mesma, diminuem-se as despesas com mão de obra, o que colabora com o aumento dos lucros da empresa.

O planejamento e o controle dizem respeito às atividades que tentam conciliar as demandas do mercado e à habilidade dos recursos de produção de entregá-la em tempo hábil. (SLACK, BRANDON-JONES e JOHNSTON, 2016).

\subsubsection{DIFICULDADES NA IMPLANTAÇÃO DO PCP}

São muitas as dificuldades na implantação do PCP.

Uma das maiores dificuldades para o desempenho da função PCP refere-se a relacionamentos. Por administrar informações de diversas áreas, o PCP está em constante processo de negociação com os diferentes agentes dentro do processo produtivo. O PCP é o representante da área de vendas dentro da fábrica, é ele quem sabe das prioridades e prazos de entrega dos produtos aos clientes e faz a programação de modo que atenda a esse objetivo. No entanto, os interesses são antagônicos, enquanto a produção quer uma programação estável e antecipada de grandes lotes, vendas quer maior flexibilidade e diversidade para atender as constantes mudanças no mercado. Como manter níveis de produção estáveis se a demanda é totalmente instável? Talvez algum dia alguém queira responder a essa 
questão, ainda mais quando se trata de administrar recursos escassos. O PCP precisa ponderar esses diferentes interesses fazendo com que a produção atenda ao planejamento, otimizando ao máximo os recursos sem deixar de atender ao cliente, no caso, o departamento de vendas (CARMELITO, 2008, p. 1).

O mau planejamento para a aquisição de matéria-prima e a falta de material pode gerar muitos transtornos e, muitas vezes, parar a produção. (PEREIRA, BARBOSA e DROHOMERETSKI, 2012).

A falta de mão de obra e de recursos financeiros também dificultam a implantação do PCP, pois esse processo demanda qualificação, tempo e dinheiro. É mister uma boa estrutura organizacional para a implantação do PCP, pois ela levará a grandes mudanças na organização. (MACHILINE, 1978).

Outro ponto a ser destacado como dificuldade de implantação do PCP é a insatisfação dos colaboradores, pois o processo exige o esforço coletivo e muita força de vontade para que seja alcançado com sucesso, o que nem sempre acontece, tornando-se, assim, uma dificuldade. (MACHLINE, 1978).

\section{METODOLOGIA}

Para responder ao problema e atingir aos objetivos desta pesquisa foi realizado um estudo de caso em uma empresa de confecção sediada na cidade mineira de Divinópolis. Gil (1991) descreve que o estudo de caso consiste em estudo exaustivo de poucos objetos, o que permite um maior conhecimento do mesmo.

[...] o delineamento se fundamenta na ideia de que a análise de uma unidade de determinado universo possibilita a compreensão da generalidade do mesmo ou, pelo menos, o estabelecimento de bases para uma investigação posterior, mais sistemática e precisa. (GIL, 1991, p. 79). 
Quanto aos fins, a pesquisa caracterizou-se como descritiva, pois buscou descrever a implantação do PCP e seus benefícios.

As pesquisas descritivas têm como objetivo primordial a descrição das características de determinada população ou fenômeno ou, então, o estabelecimento de relações entre variáveis. São inúmeros os estudos que podem ser classificados sob este título e uma de suas características mais significativas está na utilização de técnicas padronizadas de coleta de dados, tais como o questionário e a observação sistemática. (GIL, 2002, p. 42).

Adotou-se, também, a pesquisa qualitativa de caráter exploratório que, segundo Richardson (1999):

A abordagem qualitativa tem como objeto situações complexas ou estritamente particulares e os estudos que fazem uso desta abordagem podem descrever a complexidade de dado problema, compreender e classificar processos dinâmicos vividos por grupos sociais, possibilitar, em maior profundidade, o entendimento das particularidades do comportamento dos indivíduos. (RICHARDSON, 1999, p. 39).

O universo da pesquisa foi uma Confecção sediada no município de Divinópolis (MG). A amostra foi representada pelo assistente de PCP, o gerente de produção e três diretores.

Foi feita uma pesquisa bibliográfica, buscando referências em autores diversos através de livros, artigos, monografias e dissertações disponíveis na internet.

Os instrumentos utilizados para a coleta de dados foram documentos, observações e entrevistas semiestruturadas. 
Os dados foram coletados através de entrevistas, feitas individualmente, no local de trabalho. Os entrevistados foram: Antônio Melo, Assistente de PCP; Geraldo Magela, Gerente de Produção e três Diretores da empresa.

Haguette, 1997 (apud Miranda, 2009, p. 42) define entrevista como "um processo de interação social entre duas pessoas na qual uma delas, o entrevistador, tem por objetivo a obtenção de informações por parte do outro, o entrevistado".

A entrevista permite, de acordo com Miranda (2009) respostas mais abrangentes, possuem mais elasticidade quanto à duração e permite aprofundar o assunto. É melhor a interação entre o entrevistador e o entrevistado, ao favorecer respostas mais espontâneas. Entretanto, possui a desvantagem em limitar o entrevistador, como o tempo disponível além de poder provocar insegurança por parte do entrevistado como o anonimato, fazendo com que ele retenha informações.

Após o levantamento dos dados foram realizadas a interpretação e a análise dos mesmos.

\section{RESULTADOS E DISCUSSÕES}

Várias questões sobre o processo produtivo da confecção foram coletados, através da aplicação de entrevistas com o assistente de PCP, o gerente de produção e os três diretores da empresa.

\subsection{ASSISTENTE DE PCP}

Perfil do Assistente de PCP: é do sexo masculino, tem 27 anos, trabalha na empresa há 2 anos e está cursando segundo período em engenharia de produção.

Segundo o assistente de PCP, as principais dificuldades na implantação encontramse na resistência a novas ideias e mudanças por parte da organização, o que dificulta vislumbrar um resultado a longo prazo. Em contra partida, o PCP tem, como vantagens, a disposição dos funcionários em ajudar e desenvolver bons trabalhos. 
Perguntado sobre os benefícios proporcionados pela implantação do PCP, enumerou: organização e planejamento da produção, entrega de pedidos mais dentro dos prazos estipulados.

Considera que o PCP da indústria de confecção ainda não se encontra bem estruturado e necessita de um funcionário específico para a área.

A diretoria, ao mesmo tempo em que deseja resultados imediatos, tem resistência na implantação do PCP pela exigência de um tempo para sua criação.

Indagado se os processos de produção estão estruturados, respondeu que em parte, porque os ambientes de trabalho são bem estruturados, as ferramentas disponíveis estão velhas e muitos funcionários não têm funções específicas.

A confecção possui cinquenta funcionários e uma média de produção de 25.000 peças.

Segundo o entrevistado, a confecção possui grande estocagem de matéria prima, mas seu controle é ineficiente. Atualmente, percebe-se uma melhoria no seu planejamento; compra-se apenas o necessário e sua estocagem está diminuindo.

Em relação à limpeza da produção, afirma que não é limpa, precisa de mais organização, implantação de ferramentas para conscientização dos colaboradores e limpeza do local.

Quanto aos treinamentos, houve um, juntamente com o SENAI Divinópolis. Entretanto, foi pouco aproveitado devido à resistência da empresa.

\subsection{GERENTE DE PRODUÇÃO}

Perfil do Gerente de Produção: é do sexo masculino, tem 45 anos, trabalha na empresa há 5 anos e tem ensino superior completo em administração. 
Para o gerente de produção, as principais dificuldades encontradas na implantação do PCP são: resistência a mudança por parte da diretoria, falta de treinamento para os funcionários designados para o PCP, interrupção do processo, relacionamento entre o vendas e a produção, não atendimento à demanda.

Considera que as facilidades encontradas estão nos funcionários, pois desejam o PCP, considerando-o uma grande ajuda na melhoria da produção; consciência do pessoal da produção de que o PCP irá trazer muitos benefícios.

Dentre os benefícios estão a organização, controle, entrega na data certa, apesar de ainda existir dificuldades de comunicação entre vendas e produção com o PCP.

Segundo o gerente de produção ainda não há uma boa estruturação no PCP. Ele se encontra em processo de implantação. Devido às resistências, mau relacionamento entre vendas e produção e falta de treinamento, ele ainda não se estruturou por completo. Há muitas falhas como atraso na entrega de pedidos, produzir correndo, entre outros.

A diretoria tem resistência na implantação do PCP. Muitas vezes, o atraso na entrega dos produtos, faz com que a diretoria pense que o PCP pode atrapalhar o andamento e que alguns momentos deve parar a implantação e produzir em menor tempo, gerando conflitos.

Os processos de produção estão estruturados, mas é preciso designar mais funcionários para o PCP, trocar algumas ferramentas que são velhas e antigas.

A média mensal da produção da empresa gira em torno de 25.000 peças.

Inexiste um controle eficiente da matéria prima; o estoque é muito grande. Já está sendo feito um trabalho de reestruturação.

A produção não é limpa; está suja e precisa ser implantado um melhoramento e a limpeza da mesma. 
Em relação a treinamentos, o gerente de produção afirma ter tido somente um treinamento, necessita-se de mais.

\subsection{DIRETORES DA EMPRESA}

Perfil da Diretoria: ambos são sexo masculino, o DIRETOR 1 tem 62 anos, o DIRETOR 2, 52 anos e o DIRETOR 3, 49 anos. Trabalham na empresa desde a fundação, ou seja, 30 anos. O DIRETOR 1 tem ensino médio completo, o DIRETOR 2, ensino superior em andamento em gestão de negócios e, o DIRETOR 3, ensino superior completo em administração.

Foi questionado aos diretores da empresa sobre a existência de dificuldades e de facilidades na implantação do PCP.

Dentre as dificuldades, foram lembradas: o relacionamento entre o setor de vendas e o setor da produção, um pouco complicado; o vendas vende e a produção algumas vezes não está estruturada para produzir a quantidade vendida; há um conflito $\mathrm{e}$, muitas vezes, atraso na entrega, o que não acontece com frequência, apenas algumas vezes. O estoque está em estruturação, o que ocasiona uma certa confusão; às vezes, falta matéria prima. É preciso encontrar profissionais mais qualificados para trabalhar na implantação do PCP, muitas vezes há falhas e o que ocasiona perda de produção e atraso na entrega.

Dentre as facilidades, foram citadas: organização do estoque, que ainda possui falhas; mais treinamentos e procura de profissionais qualificados.

São benefícios que proporcionam a implantação do PCP: diminuição de atrasos na entrega, apesar de ainda existir falhas na produção; organização da produção e aumento de visão por parte de todos os envolvidos.

Segundo os diretores, o PCP só está bem estruturado em parte. A empresa passa por um processo de implantação. Entretanto, é preciso ir devagar para não atropelar os processos, não ferir a cultura da empresa e treinar mais os colaboradores. 
A diretoria não apresenta resistência à implantação do PCP. Mas relatam que "apenas não queremos fazer todas as mudanças ao mesmo tempo, temos que ir experimentando aos poucos para ver o que funciona e o que não funciona, precisamos organizar em partes. E vamos devagar. Temos que preparar mais os funcionários também" (DIRETOR 2).

Os processos de produção estão se estruturando, aos poucos. Existem muitas falhas e funcionários que precisam ser treinados.

A média de produção da empresa é de 25.000 peças.

Quanto ao controle da matéria prima, a empresa possui um estoque muito grande, exigindo um trabalho de reestruturação.

A produção não é limpa. "Após a implantação do $\mathrm{PCP}$, vamos organizar e implantar o 5S" (DIRETOR 3).

Até hoje, só foi realizado um treinamento para ferramentas de planejamento. Há necessidade de mais treinamentos.

Após a aplicação e a análise dos resultados viu-se que o PCP é eficaz para todas as organizações para que possam exercer, com segurança e qualidade, suas atividades a fim de atenderem seus clientes e se fortalecerem no mercado onde estão inseridas.

Houve uma uniformidade das respostas dadas tanto pelo assistente de PCP, o gerente de produção e três diretores da empresa. Em relação às dificuldades, houve uma convergência de ideias sobre o que foi narrado por Carmelito (2008); Pereira, Barbosa e Drohomeretski (2012) e Machiline (1978). Um único fator apontado, por Machiline (1978), como dificuldade - insatisfação dos colaboradores - não condiz com o resultado da pesquisa que expõe que, dentre as facilidades encontradas estão os funcionários, pois desejam o PCP, considerando-o uma grande ajuda na melhoria da produção.

Sobre as vantagens também houve um consenso entre os respondentes. 
Em relação aos benefícios, objetivo principal desse estudo, foram lembrados: organização e planejamento da produção, entrega de pedidos mais dentro dos prazos estipulados; organização, controle, entrega na data certa, apesar de ainda existir dificuldades de comunicação entre vendas e produção com o PCP; diminuição de atrasos na entrega, apesar de ainda existir falhas na produção; organização da produção e aumento de visão por parte de todos os envolvidos. As respostas são condizentes ao pensamento de Bock, Ferrari, Nara e Kipper (2015); Chiavenato (2005) que consideram que, através do PCP, os materiais necessários chegam corretamente e em quantidade exata até a linha de montagem, para que sejam eliminadas as chances de desperdícios.

Segundo Oliveira (2015), para atingir os resultados esperados, deve-se respeitar alguns princípios, como o da contribuição aos objetivos, da precedência do planejamento, das maiores influências e abrangência e da maior eficiência, eficácia e efetividade. As respostas fornecidas pelos entrevistados mostram que, nem sempre, esses princípios são respeitados, pois o PCP da indústria de confecção ainda não se encontra bem estruturado; há necessidade de funcionários específicos para a área; a diretoria, ao mesmo tempo em que deseja resultados imediatos, tem resistência na implantação do PCP pela exigência de um tempo para sua criação; as ferramentas disponíveis estão velhas; não há um bom relacionamento entre vendas e produção; falta treinamento; falhas como atraso na entrega de pedidos, produzir correndo, entre outros. Segundo os diretores, não há resistência à implantação do PCP, por parte deles, o que contraria a opinião do assistente de PCP e do gerente de produção.

A produção não é limpa. "Após a implantação do $\mathrm{PCP}$, vamos organizar e implantar o 5S" (DIRETOR 3). E, de acordo com a resposta dada existe um desacordo com o conceito de administração de produção e operações que se referem às funções administrativas clássicas (planejar, organizar, dirigir e controlar) aplicadas às atividades envolvidas com a produção de um produto ou à prestação de serviço. Como os conceitos e técnicas aplicam-se à tomada de decisão, facilita a aquisição de melhores resultados (MOREIRA, 2016). Para atingir plenamente esse conceito na 
empresa é visível que a organização e a implantação do PCP ocorra o mais rápido possível.

Apesar da empresa conhecer as dificuldades, vantagens, benefícios do PCP, percebe-se que ela ainda não se encontra estruturada de modo a atingir seus objetivos e objetivos do PCP, que têm grande importância dentro de uma empresa ao coordenar recursos que interferem nos resultados da organização e auxiliar para que haja qualidade nos seus resultados. (PEREIRA, BARBOSA e DROHOMERETSKI, 2012).

\section{CONCLUSÃO}

A empresa de confecção em estudo é muito resistente a mudanças, apesar de todas as dificuldades encontradas, o PCP está adquirindo seu espaço, observa-se que a estocagem de matéria prima reduziu, os pedidos já são entregues dentro do prazo estipulado e o que mais atrapalha o andamento da empresa é o acréscimo de peças de pronta entrega na produção.

Apesar da estrutura precária do PCP e equipamentos velhos, os funcionários, muitos até sem função específica, procuram da melhor forma possível atender as necessidades da empresa.

O problema: "Quais os benefícios da implantação do PCP em uma empresa de confecção" foi solucionado, o PCP é uma importante ferramenta para a empresa, com a implantação do PCP diminui atrasos na entrega de pedidos, a produção planejada é mais organizada e ainda aumenta.

O objetivo geral foi atingido, foi descrito como se dá a implantação do Planejamento e Controle de Produção e quais os benefícios pode proporcionar em uma empresa do ramo de confecção. E ainda os objetivos específicos, o PCP foi associado a realidade da empresa, foi descrito as finalidades e as funções do PCP e identificadas as dificuldades encontradas em sua implantação. 
Com a metodologia utilizada, conclui-se que as hipóteses são verdadeiras, a empresa em estudo não tem um planejamento e controle da produção bem estruturado; as dificuldades na implantação do PCP na empresa de confecção encontram-se na resistência, por parte da diretoria, em mudar os processos. Já a hipótese que a empresa desconhece as funções e os benefícios do PCP, por acreditarem que seus processos estejam bem estruturados é falsa, a empresa reconhece que sua estrutura não é preparada e que foge um pouco do que é planejado, está em um processo de implantação e prefere ir devagar sem atropelar os processos, não ferir a cultura da empresa e treinar mais os colaboradores.

Há possibilidade de melhoria na implantação do PCP, ela apenas está lenta, sugerese então que a empresa busque ferramentas que auxiliem no controle e na programação da produção, a fim de ajudar na rotina de trabalho, garantindo maior qualidade no produto final, sem atrasos, e consequentemente, mantendo a empresa competitiva no mercado.

\section{REFERÊNCIAS}

ACKOFF, R. L. Redesigning the future: a systems aproach to societal problems. New York: John Wiley, 1974 apud OLIVEIRA, D. de P. R. de. Planejamento estratégico: conceitos metodologias e prática. 33 ed. São Paulo: Atlas, 2015.

BOCK, F. C.; FERRARI, A. G.; NARA, E. O. B.; KIPPER, L. M. Planejamento e controle da produção (PCP) como disseminador da filosofia lean nos processos organizacionais. 2015. Disponível em: < https://www.researchgate.net/publication/ > Acesso em 30 de agosto de 2017.

CARMELITO, R. As dificuldades do PCP (Planejamento e controle de produção). 2008. Disponível em: < http://www.administradores.com.br/artigos/negocios/asdificuldades-do-pcp-planejamento-e-controle-de-producao/26334/>. Acesso em: 9 setembro 2017. 
CHIAVENATO, I. Administração da Produção: uma abordagem introdutória. 4 ed. Rio de Janeiro: Elsevier, 2005.

CORRÊA, H. L; CORRÊA, C. A. Administração da produção e operações: manufatura e serviços: uma abordagem estratégica. 3 ed. São Paulo: Atlas, 2012.

GIL, A. C. Como elaborar projetos de pesquisa. 4. ed. São Paulo: Atlas, 2002.

Métodos e técnicas de pesquisa social. São Paulo: Atlas, 1991.

Haguete, T. M. F. (1997) Metodologias qualitativas na Sociologia. 5. a edição. Petrópolis: Vozes apud MIRANDA, R. J. P. Qual a relação entre o pensamento crítico e a aprendizagem de conteúdos de ciências por via experimental? um estudo no $1^{\circ}$ Ciclo. Tese de mestrado, Educação (Didática das Ciências), Universidade de Lisboa, Faculdade de Ciências, 2009. Disponível em:

<http://repositorio.ul.pt/bitstream/10451/5489/9/ulfc096328_3_metodologia.pdf>. Acesso em: 10 set. 2017.

MACHLINE, C. Manual de administração da produção. 4 Ed. Rio de Janeiro: Fundação Getúlio Vargas, 1978.

MIRANDA, R. J. P. Qual a relação entre o pensamento crítico e a aprendizagem de conteúdos de ciências por via experimental? um estudo no $1^{\circ}$ Ciclo. Tese de mestrado, Educação (Didática das Ciências), Universidade de Lisboa, Faculdade de Ciências, 2009. Disponível em:

<http://repositorio.ul.pt/bitstream/10451/5489/9/ulfc096328_3_metodologia.pdf>. Acesso em: 10 set. 2017.

MOREIRA, D. A. Administração da produção e operações. 2 ed. São Paulo: Cengage Learning, 2016. 
OLIVEIRA, D. de P. R. de. Planejamento estratégico: conceitos metodologias e prática. 33 ed. São Paulo: Atlas, 2015.

PEREIRA, G. R.; BARBOSA, W. D.; DROHOMERETSKI, E. Planejamento e controle da produção: um estudo à luz da produção científica. 2012. Disponível em: < http://www.abepro.org.br/biblioteca/enegep2012 > Acesso em 30 de agosto de 2017.

RUSSOMANO, V. H. Planejamento e Controle da Produção. 5. edição, rev. São Paulo: Pioneira, 1995 apud BOLSI, P. de F. Diagnóstico: Planejamento e controle da produção nas pequenas e médias indústrias de alimentos do extremo oeste de Santa Catarina, 2011. Disponível em: < http://www.uniedu.sed.sc.gov.br/trabalhos/diagnostico-planejamento-e-controle-daproducao-nas-pequenas-e-medias-industrias-de-alimentos-do-extremo-oeste-desanta-catarina/> Acesso em: 07 de setembro de 2017.

PORTOPÉDIA. PCP - Planejamento e Controle da Produção. 2016. Disponível em: $<$ https://portogente.com.br/portopedia/78470-pcp-planejamento-e-controle-daproducao>. Acesso em: 9 set. 2017.

RICHARDSON, R. J. Pesquisa social: métodos e técnicas. 3. ed. São Paulo: Atlas, 1999.

ROCHA, T. G.; GALENDE, S. B. A importância do controle de qualidade na indústria farmacêutica. 2014. Disponível em: < https://www.mastereditora.com.br/periodico/ > Acesso em 30 de agosto de 2017.

SLACK, N.; BRANDON-JONES, A.; JOHNSTON, R.; tradução Ailton Bonfim Brandão. Administração da produção. 4 ed. São Paulo: Atlas, 2016.

TUBINO, D. F. Manual de Planejamento e Controle da Produção. 2. Edição. São Paulo: Atlas, 2000 apud BOLSI, P. de F. Diagnóstico: Planejamento e controle da produção nas pequenas e médias indústrias de alimentos do extremo oeste de Santa Catarina, 2011. Disponível em: < 
http://www.uniedu.sed.sc.gov.br/trabalhos/diagnostico-planejamento-e-controle-daproducao-nas-pequenas-e-medias-industrias-de-alimentos-do-extremo-oeste-desanta-catarina/> Acesso em: 07 de setembro de 2017.

\section{APÊNDICE}

Apêndice A - Entrevista

1) Sexo: ( ) Masculino ( ) Feminino

2) Idade: 3) Tempo de Serviço: 4) Escolaridade:

5) Quais são as dificuldades encontradas na implantação do PCP?

6) Quais as facilidades?

7) Que benefícios estão proporcionando a implantação do PCP?

8) O Planejamento e Controle da Produção estão bem estruturados?

9) A diretoria tem resistência na implantação do PCP?

10) Os processos de produção estão estruturados?

11) Qual é a média mensal da produção da empresa?

12) Existe controle da matéria prima?

13) A produção é limpa?

14) Há treinamentos para ferramentas de planejamento? 